\title{
The Effects of Selected Aerobic Exercises on Pulmonary Functions of High School Obese Girls
}

\author{
Khadijeh Irandoust ${ }^{1, *}$ \\ ${ }^{1}$ Department of Physical Education, Imam Khomeini International University, Qazvin, IR Iran \\ *Corresponding author: Khadijeh Irandoust, Department of Physical Education, Imam Khomeini International University, Qazvin, IR Iran. Tel: +98-2833780021, Fax: +98-2833780084, \\ E-mail: parirandoust@gmail.com
}

Received: April 18, 2015; Accepted: June 6, 2015

\begin{abstract}
Background:Aerobic exercise is an important component of pulmonary functions for obese adolescents. There are few studies on aerobic exercise and pulmonary function in obese adolescence.

Objectives: The purpose of this study was to investigate the effect of selected aerobic exercise training on some pulmonary function of Iranian obese girls.

Patients and Methods: Forty-five, apparently obese adolescence, aged 14 - 15 years were randomly divided into three groups (15 subjects in each group) including rope skipping; jogging and control groups. Experimental groups participated in a twelve-week program ( 3 sessions a week, each session for 45 minutes) while control group had no plan of exercise. A spirometry test was taken 24 hours before and after the training protocol. Statistical analysis using the one-way analysis of variance was used $(\mathrm{P}<0.05)$.

Results: The results suggested that all anthropometric characteristics of both experimental groups including weight, body mass index (BMI), percent body fat (PBF), waist-hip ratio (WHR) were significantly improved after exercise protocol, furthermore, ventilation capacity (VC), forced vital capacity (FVC), forced expiratory volume in the first second (FEV1) were significantly improved in experimental groups compared to control group $(\mathrm{P}<0.001)$, while no significant difference was found between two experimental groups in ventilation functions $(\mathrm{P}>0.001)$.
\end{abstract}

Conclusions: We conclude that appropriate aerobic exercise can improve lung function in obese adolescence.

Keywords: Jogging; Spirometry; Rope Skipping

\section{Background}

Obesity is one of the most frequently found health risks and the prevalence of obesity is rapidly escalating globally in all age groups (1). In healthy teenagers, obesity and physical inactivity are the two main factors that affect respiratory function $(2,3)$. The major respiratory complications of obesity include a heightened demand for ventilation, intensified breathing, respiratory muscle inefficiency and diminished respiratory compliance. The most characteristic changes in pulmonary function in obese persons are decreased functional residual capacity and expiratory reserve volume (4).

Studies have revealed a significant reduction in VC, FVC, FEV1 in the obese persons (5). Moreover, reductions in pulmonary function in relation to the waist-to-hip ratio has been observed in the obese adult (6). Abdominal obesity is often correlated with reduced FVC and FEV1 (7). It has been demonstrated that Regular physical activity of adequate intensity and duration can result in a number of potential beneficial effects on general health (8). However, obese adolescence tend to show less tolerance to daily activities and exercise due to sedentary lifestyle and therefore be inclined to have lower aerobic fitness and consequently lower pulmonary functions than their normal peers $(9,10)$. If these exercises are done at schools, the synergy caused by peers can result in better tolerance of exercise intensity.

It is generally accepted that forced expiratory volume in one second (FEV1) and Forced vital capacity (FVC) are strong indicators of lung function, which decline due to obesity and sedentary life style (11). These observations suggest that overweight and obese adolescents are at a higher risk for deterioration of their respiratory indices and may be at risk for developing chronic obstructive pulmonary disease in adulthood $(2,4)$. Hence, appropriate interventions, such as prescribed physical activity programs, may prevent lung function deterioration in these young subjects. Numerous exercise approaches have been designed with the intention of controlling weight in adolescence $(3,9)$. Evidence suggests that jogging can effectively improve the pulmonary functions in obese adolescents (12). On the other hand, rope skipping is of much interest among Iranian girls and frequently is performed at physical education classes at Iranian schools.

Copyright (c) 2015, Health Policy Research Center. This is an open-access article distributed under the terms of the Creative Commons Attribution-NonCommercia 4.0 International License (http://creativecommons.org/licenses/by-nc/4.0/) which permits copy and redistribute the material just in noncommercial usages, provided the original work is properly cited. 


\section{Objectives}

The present study intends to investigate the effects of rope skipping and jogging exercises on pulmonary functions of Iranian obese girls, because it has been hypothesized that these two popular training protocols as a weight-loss program would significantly decrease general and abdominal obesity and consequently improve pulmonary functions in the obese girls.

\section{Patients and Methods}

This was a simple randomized clinical trial conducted on 45 obese adolescents, aged from 14 - 15 years, attending the first to the second year of high school of Pegah high school, Qazvin, Iran, during the 2013 school year (Figure 1). This study was approved by ethics committee of the institute and by the principal of the school. The written informed consent was obtained from all subjects who had been briefed about the research procedures.

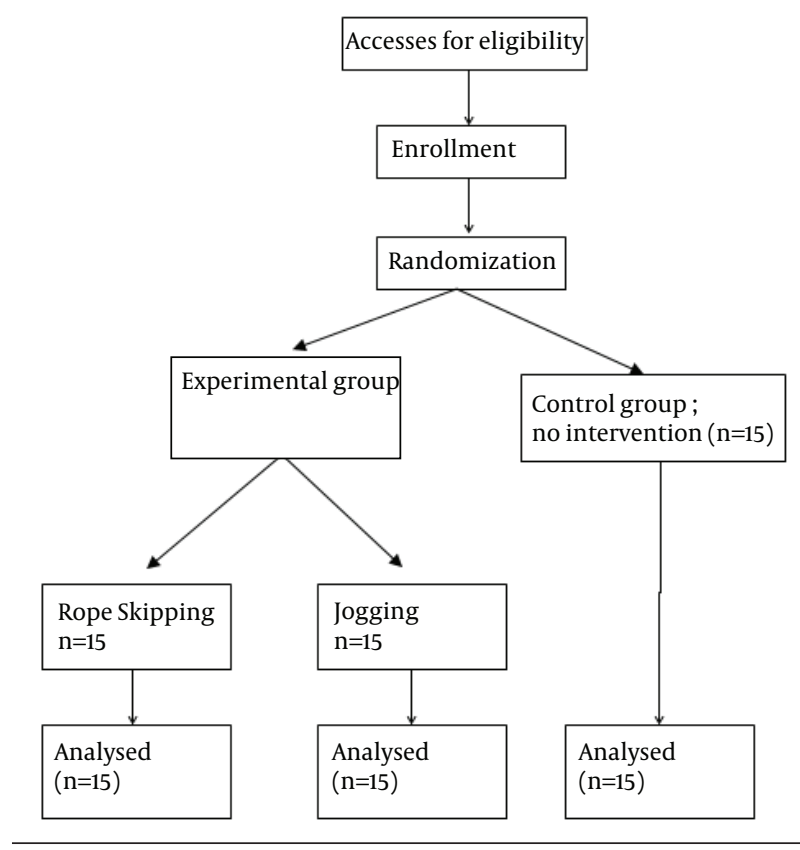

Figure 1. Recruitment and Allocation of the Study Participants

\subsection{Exclusion Criteria}

Exclusive criteria for the study included cardiovascular disease; permanent or temporary physical disabilities that prevented ventilation and anthropometric measurements and the performance of physical exercise; orthopedic limitations; absence at over $25 \%$ of physical education classes during the study. All participants had no more than one hour regular physical activity program during the week.

\subsection{Sampling Procedures}

The population of students enrolled in high school in 2013 consisted of 164 students distributed in 4 classes (first, second years). Their PBF was measured as an obe- sity index by body composition analyzer (ZENUS 9.9 PLUS Model). The PBF higher than 30\% was considered as obesity. After measurements, PBF of 53 students were above $30 \%$. The stratification process was done by simple randomization in classes, divided into three groups of rope skipping; jogging and control groups. The final study population consisted of 45 students, 15 in each of the rope skipping, jogging and control groups.

\subsection{Intervention}

Experimental groups participated in a twelve-week program (3 sessions a week, each session for 45 minutes) while control group had no plan of exercise. The training protocol for rope skipping group was 15 minutes warmup, 25 minutes rope skipping and 5 minutes cool-down. The second experimental group involved 25 minutes sessions of jogging with 15 minutes of warm-up exercise before jogging and 5 minutes of cool-down exercise after the practice. Training intensity was controlled by Polar Electro, Kempele, Finland. A spirometry test was taken 24 hours before and after the training protocol. Subjects were asked to refrain from tea, coffee, chocolates and caffeinated soft-drinks on the day of recording Spirometry and for the duration of exercise.

\subsection{Measurements}

Ventilatory function test: spirometer (Cosmed Pony FX Spirometer) was used to measure lung function testing, including ventilation capacity (VC), forced vital capacity (FVC), and forced expiratory volume in the first second (FEV1). These respiratory function tests were performed by the same therapist. BMI, PBF, and WHR of the participants were measured by body composition analyzer (ZENUS 9.9 PLUS Model). Statistical analysis using the oneway analysis of variance was used and $P$ value $<0.05$ was considered as significant.

\section{Results}

At baseline, there were no significant differences between all variables in three groups $(\mathrm{P}>0.05)$. As shown in Table 1, significant mean differences were found between experimental and control groups in all anthropometric characteristics. Tukey's post-hoc test showed that all anthropometric characteristics of both experimental groups (weight, BMI, PBF, WHR (Figure 2) were significantly improved after exercise protocol $(\mathrm{P}=0.001)$, while no significant difference was found between the two experimental groups in weight $(\mathrm{P}=0.21)$, $\mathrm{BMI}(\mathrm{P}=0.27)$, $\mathrm{PBF}$ $(\mathrm{P}=0.42)$, and WHR $(\mathrm{P}=0.77)$.

As shown in Table 2, significant differences were found between experimental and control groups in respiratory function. Tukey's post-hoc test showed that VC, FVC, FEV1 were significantly improved in experimental groups compared to control group ( $\mathrm{P}=0.001$; Figure 3 ) while no significant difference was found between two experimental groups in VC $(\mathrm{P}=0.06)$, FVC $(\mathrm{P}=0.09)$, and FEV1 $(\mathrm{P}=0.77)$. 


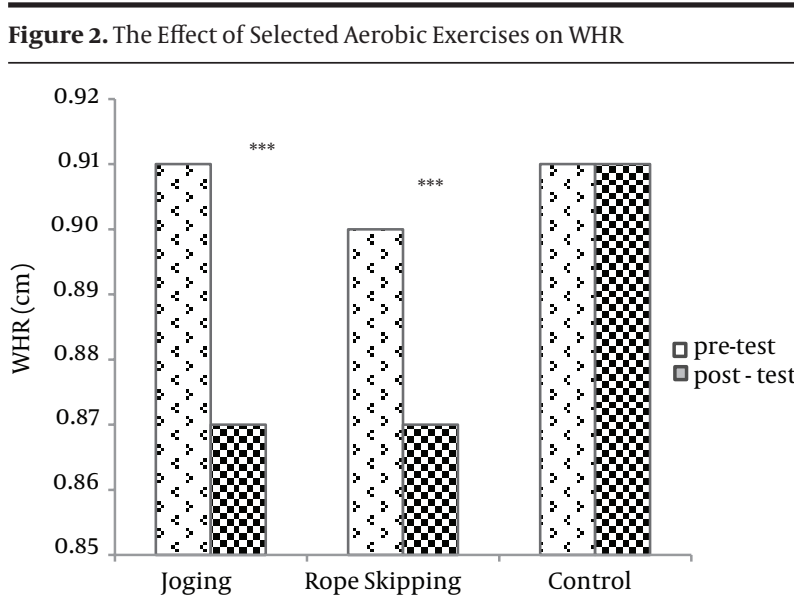

*** Significant difference between experimental and control groups, $\mathrm{P}<$ 0.001 .
Figure 3. Mean Differences of Ventilation Capacities in Pre-Test and Post-Test

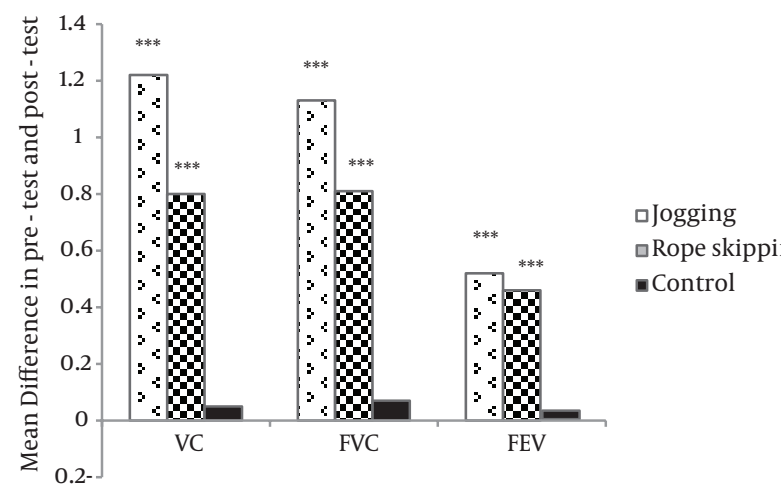

*** Significant difference between experimental and control groups, $\mathrm{P}<$ 0.001 .

\begin{tabular}{|c|c|c|c|c|c|c|c|c|}
\hline \multirow[t]{3}{*}{ Group Variables } & \multicolumn{4}{|c|}{ Experimental } & \multirow{2}{*}{\multicolumn{2}{|c|}{ Control }} & \multirow[t]{3}{*}{$\mathbf{F}$} & \multirow[t]{3}{*}{$\mathbf{P}^{\mathrm{b}}$} \\
\hline & \multicolumn{2}{|c|}{ Jogging } & \multicolumn{2}{|c|}{ Rope Skipping } & & & & \\
\hline & Pre-Test & Post-Test & Pre-Test & Post-Test & Pre-Test & Post-Test & & \\
\hline Age, $y$ & $14.4 \pm 0.5$ & - & $14.4 \pm 0.5$ & - & $14.6 \pm 0.5$ & - & - & - \\
\hline Weight, kg & $74.0 \pm 2.4$ & $70.8 \pm 2.5$ & $73.0 \pm 3.0$ & $70.4 \pm 2.9$ & $72.0 \pm 2.8$ & $71.9 \pm 2.3$ & 47.025 & 0.001 \\
\hline BMI, $\mathrm{Kg} / \mathrm{m}^{2}$ & $28.4 \pm 0.99$ & $27.1 \pm 1.05$ & $28.5 \pm 1.2$ & $27.5 \pm 1.2$ & $28.1 \pm 1.4$ & $28.1 \pm 1.2$ & 46.978 & 0.001 \\
\hline Percent Body Fat, \% & $33.4 \pm 1.4$ & $30.8 \pm 1.7$ & $32.5 \pm 1.8$ & $30.2 \pm 1.6$ & $32.5 \pm 2.2$ & $32.4 \pm 1.8$ & 38.111 & 0.001 \\
\hline WHR, cm & $0.91 \pm 0.09$ & $0.87 \pm 0.01$ & $0.90 \pm 0.01$ & $0.87 \pm 0.01$ & $0.91 \pm 0.08$ & $0.91 \pm 0.08$ & 27.409 & 0.001 \\
\hline
\end{tabular}

a Data are expressed as mean \pm SD.

b Significant mean difference between experimental and control groups.

Table 2. Pre and Post Exercise Respiratory Function of the Experimental and Control Groups a,b

\begin{tabular}{|c|c|c|c|c|c|c|c|c|}
\hline \multirow[t]{3}{*}{ Group Variables } & \multicolumn{4}{|c|}{ Experimental } & \multirow{2}{*}{\multicolumn{2}{|c|}{ Control }} & \multirow[t]{3}{*}{$\mathbf{F}$} & \multirow[t]{3}{*}{$\mathbf{P}^{\mathrm{C}}$} \\
\hline & \multicolumn{2}{|c|}{ Jogging } & \multicolumn{2}{|c|}{ Rope skipping } & & & & \\
\hline & Pre-Test & Post-Test & Pre-Test & Post-Test & Pre-Test & Post-Test & & \\
\hline VC, $\mathrm{L}$ & $3.20 \pm 0.21$ & $4.42 \pm 0.67$ & $3.28 \pm 0.36$ & $4.08 \pm 0.36$ & $3.21 \pm 0.5$ & $3.27 \pm 0.28$ & 22.232 & 0.001 \\
\hline FVC, L & $3.27 \pm 0.18$ & $4.41 \pm 0.44$ & $3.38 \pm 0.22$ & $4.20 \pm 0.36$ & $3.05 \pm 0.46$ & $3.12 \pm 0.37$ & 26.18 & 0.001 \\
\hline FEV1, L & $3.19 \pm 0.18$ & $3.72 \pm 0.35$ & $3.24 \pm 0.39$ & $3.71 \pm 0.34$ & $3.27 \pm 0.28$ & $3.24 \pm 0.24$ & 2.285 & 0.001 \\
\hline
\end{tabular}

${ }^{\text {a }}$ Data are expressed as mean \pm SD.

b Abbreviations: VC, Ventilation Capacity; FVC, forced expiratory volume; FEV1, forced expiratory volume in one second.

c Significant difference between experimental and control groups.

\section{Discussion}

Obesity is considered a chronic disease and directly or indirectly related to some other pathological situations which contribute to respiratory diseases (13). Thus, the purpose of this study was to investigate the effects of selected aerobic exercises with the intention of body fat weight loss on pulmonary functions of obese girls. The results demonstrated that ventilation variables (VC, FVC, and FEV1) were significantly improved after exercise protocol compared to control group. As cited, obesity is ex- pected to alter respiratory function, because of visceral fat which surrounds the lung and narrows the airway (14). This stresses the idea that any intervention which lead to adipose tissue reduction, can probably improve the pulmonary functions.

As shown, all anthropometric indices related to obesity (BMI, PBF, and WHR) were decreased after exercise interventions which can justify why the ventilation functions of subjects have been improved. As suggested, WHR as an 
indicator of visceral fat was significantly decreased after exercise, thus one explanation for the improved ventilation functions can be attributed to reduced WHR.

The findings of this study are consistent with the results of a study by Farrell et al (15), who found that FVC and FEV1 were improved after 8 weeks of aerobic training. Most of the respiratory function abnormalities seen in obesity are due to the mechanical load of adipose tissue on the chest wall and also muscular imbalances-associated with inactivity imposing restriction on the thorax (16), So any weight-loss training (fat loss) may compensate for this situation; furthermore, the improvement of the respiratory muscles is another beneficial effect of regular exercise training (17). Exercise improves lung function by enhancing the exchange of gasses in the alveoli and elevating the absorption of oxygen from the bloodstream $(9,12,15)$. In obese individuals, the hyper-responsiveness to exercise may be explained by three hypotheses. The first one is supported by the differences in anatomy of the lungs and airways in obese people due to the deposition of adipose tissue in the thoracic and abdominal regions (18). Which probably lead to reduction of the pulmonary function.

In the second hypothesis, the increase of adipose tissue in the abdominal and thoracic region causes reduction in the functional residual capacity (18), which directly acts on the respiratory muscles (19). The third postulate is that obesity is related to a chronic inflammatory process, since adipose tissue contributes to the production of TNF- $\alpha$ Interlokin 1, 6 and C-reactive protein which all negatively affect the pulmonary system (19). According to previous studies, aerobic exercise plays a key role in reducing the inflammatory responses produced by adipose tissue (20-22). The study of Littleton SW showed no correlation between BMI and pulmonary function test parameters (7). Which is not in agreement with our study. It is known that BMI reflects not only adipose tissue, but also muscles and bones. Therefore, the association between BMI and pulmonary function may be due, in part, to the strength of respiratory muscles.

It has been shown that the fat distribution pattern is more representative when compared only to the BMI (6). Abdominal obesity is often correlated with reduced FVC and FEV $(7,23)$. In the present study, obese adolescents had increased concentrations of abdominal fat, a fact observed during the measurement of waist circumference which was decreased significantly after exercise intervention. This is in agreement with the results of study conducted by Babb et al. (24). Who reported that modest weight loss improves breathing mechanics during submaximal exercise the improvement appears to be related to the cumulative loss of chest wall fat. But Faria et al. (25) explained that in spite of differences in lung growth, the model of fat distribution alters pulmonary function differently in obese female and male adolescents. Obese adolescents presented changes in pulmonary function at rest and these changes remained during exercise

It seems that the puberty factors should be considered for evaluating the impact of physical training in pulmonary functions of obese girls. On the other hand, the effects of physical activity intervention on body composition should be interpreted with caution. In this context, the assessment of the nutritional status using these indices during puberty has shown morphological differences, mainly during the sexual maturation stage. Changes in body mass may be typical of a certain stage of maturation and not the result of physical activity levels $(26,27)$. Therefore, further studies are needed to assess the beneficial effects of various forms of physical activity and response with long term follow up. Thus, according to the results of this study, twelve weeks of rope skipping and jogging training can significantly improve pulmonary functions in young obese female students. In conclusion, this study shows that a course of aerobic exercise causes an obvious increase in VC, FEV1, and FVC in obese girls.

\section{Acknowledgements}

We thank all of the students who voluntarily participated in this study.

\section{References}

1. Ebbeling CB, Pawlak DB, Ludwig DS. Childhood obesity: publichealth crisis, common sense cure. Lancet. 2002;360(9331):473-82.

2. Silva LO, Silva P, Nogueira AMOC, Silva MB, Luz GCP, Narciso FV, et al. Evaluation of exercise-induced bronchospasm assessed by Peak Flow Meter in obese adolescents. Revista Brasileira de Medicina do Esporte. 2011;17(6):389-91.

3. DeLorey DS, Wyrick BL, Babb TG. Mild-to-moderate obesity: implications for respiratory mechanics at rest and during exercise in young men. Int J Obes (Lond). 2005;29(9):1039-47.

4. Ray CS, Sue DY, Bray G, Hansen JE, Wasserman K. Effects of obesity on respiratory function. Am Rev Respir Dis. 1983;128(3):501-6.

5. Biring MS, Lewis MI, Liu JT, Mohsenifar Z. Pulmonary physiologic changes of morbid obesity. Am J Med Sci.1999;318(5):293-7.

6. Ceylan E, Comlekci A, Akkoclu A, Ceylan C, Itil O, Ergor G, et al. The effects of body fat distribution on pulmonary function tests in the overweight and obese. South Med J. 2009;102(1):30-5.

7. Littleton SW. Impact of obesity on respiratory function. Respirology. 2012;17(1):43-9.

8. Karacabey K. Effect of regular exercise on health and disease. Neuro Endocrinol Lett. 2005;26(5):617-23.

9. Kaufman C, Kelly AS, Kaiser DR, Steinberger J, Dengel DR. Aerobicexercise training improves ventilatory efficiency in overweight children. Pediatr Exerc Sci. 2007;19(1):82-92.

10. Baruki SBS, Rosado L, Rosado GP, Ribeiro R. Association between nutritional status and physical activity in Municipal Schools in Corumbá-MS. Revista Brasileira de Medicina do Esporte. 2006;12(2):80-4.

11. Jakes RW, Day NE, Patel B, Khaw KT, Oakes S, Luben R, et al. Physical inactivity is associated with lower forced expiratory volume in 1 second: European Prospective Investigation into Cancer-Norfolk Prospective Population Study. Am J Epidemiol. 2002;156(2):139-47.

12. Chaitra B, Vijay M. Effect of Aerobic Exercise Training on Peak Expiratory Flow Rate: a Pragmatic Randomized Controlled Trial.Int JBiol Med Res. 2011;2(3):789-92.

13. Poulain M, Doucet M, Major GC, Drapeau V, Series F, Boulet LP, et al. The effect of obesity on chronic respiratory diseases: pathophysiology and therapeutic strategies. CMAJ. 2006;174(9):1293-9.

14. Lazarus R, Colditz G, Berkey CS, Speizer FE. Effects of body fat on ventilatory function in children and adolescents: cross-sectional findings from a random population sample of school children. Pediatr Pulmonol. 1997;24(3):187-94.

15. Farrell PA. Maximal expiratory flow-volume relationships before 
and after eight weeks of endurance training. J Sports Med Phys Fitness. 1981;21(2):145-9.

16. Wright $\mathrm{P}$, Heck $\mathrm{H}$, Langenkamp $\mathrm{H}$. Effects of a resistance training on pulmonary function and performance measurements in patients with chronic obstructive pulmonary disease. EurJ Sport Sci. 2003;3(3):1-10.

17. Farid R, Azad FJ, Atri AE, Rahimi MB, Khaledan A, Talaei-Khoei M et al. Effect of aerobic exercise training on pulmonary function and tolerance of activity in asthmatic patients. Iran J Allergy Asthma Immunol. 2005;4(3):133-8.

18. Li AM, Chan D, Wong E, Yin J, Nelson EA, Fok TF. The effects of obesity on pulmonary function. Arch Dis Child. 2003;88(4):361-3.

19. Shore SA, Fredberg JJ. Obesity, smooth muscle, and airway hyperresponsiveness. JAllergy Clin Immunol. 2005;115(5):925-7.

20. Pedersen BK, Hoffman-Goetz L. Exercise and the immune system: regulation, integration, and adaptation. Physiol Rev. 2000;80(3):1055-81.

21. Fuster V, Rebato E, Rosique J, Fernandez Lopez JR. Physical activity related to forced vital capacity and strength performance in a sample of young males and females. Coll Antropol. 2008;32(1):53-60.
22. Vengata SM, Ganesh SS, Wan RW. Effect of physical activity on respiratory function in obese: A systematic review. Int J Physiother Res. 2014;2(1):342-6.

23. van Huisstede A, Cabezas MC, Birnie E, van de Geijn GJ, Rudolphus A, Mannaerts G, et al. Systemic inflammation and lung function impairment in morbidly obese subjects with the metabolic syndrome.J Obes. 2013;2013:131349.

24. Babb TG, Wyrick BL, Chase PJ, Delorey DS, Rodder SG, Feng MY, et al. Weight loss via diet and exercise improves exercise breathing mechanics in obese men. Chest. 2011;140(2):454-60.

25. Faria AG, Ribeiro MA, Marson FA, Schivinski CI, Severino SD, Ribeiro JD, et al. Effect of exercise test on pulmonary function of obese adolescents. J Pediatr (Rio J). 2014;90(3):242-9.

26. Gonçalves F, Amorim RD, Costa SMR, Lima M. The biological bases of and epidemiological evidence for the contribution of fetal and postnatal growth to body composition: a review. Revista Brasileira de Saúde Materno Infantil. 2012;12(3):223-32.

27. Bitar A, Vernet J, Coudert J, Vermorel M. Longitudinal changes in body composition, physical capacities and energy expenditure in boys and girls during the onset of puberty. Eur J Nutr. 2000;39(4):157-63. 